This is an author produced version of a paper published in Scandinavian Journal of Forest Research.

This paper has been peer-reviewed and is proof-corrected, but does not include the journal pagination.

Citation for the published paper:

Nicole Suty, Kenneth Nyström \& Göran Ståhl. (2013) Assessment of bias due to random measurement errors in stem volume growth estimation by the Swedish National Forest Inventory. Scandinavian Journal of Forest Research. Volume: ?, Number: ?, pp ?. http://dx.doi.org/10.1080/02827581.2012.734329.

Access to the published version may require journal subscription. Published with permission from: Taylor \& Francis.

Standard set statement from the publisher:

This is an Author's Accepted Manuscript of an article published in SCANDINAVIAN JOURNAL OF FOREST RESEARCH, 23 Oct 2012, copyright Taylor \& Francis, available online at: http://www.tandfonline.com/10.1080/02827581.2012.734329

Epsilon Open Archive http://epsilon.slu.se 


\section{Assessment of bias due to random measurement errors in stem volume growth estimation by the Swedish National}

\section{Forest Inventory}

Nicole Suty

Kenneth Nyström ${ }^{1}$

Göran Ståhl ${ }^{1}$

${ }^{1}$ Swedish University of Agricultural Sciences

Department of Forest Resource Management

SE-901 83 Umeå, Sweden

Corresponding author: Nicole Suty

E-mail: nicole.suty@slu.se

Tel. +46907868504

Fax +4690778116 


\section{Abstract}

We evaluated the performance of two methods for estimating stem volume increment at individual tree level with respect to bias due to random measurement errors. Here, growth is either predicted as the difference between two consecutive volume estimates where single-tree volume functions are applied to data from repeated measurements or by a regression model that is applied to data from a single survey and includes radial increment. In national forest inventories (NFIs), the first method is typically used for permanent plots, the second for temporary plots. The Swedish NFI combines estimates from both plot types to assess growth at national and regional scales and it is therefore important that the two methods provide similar results. The accuracy of these estimates is affected by random measurement errors in the independent variables, which may lead to systematic errors in predicted variables due to model non-linearity. Using Taylor series expansion and empirical data from the Swedish NFI we compared the expected bias in stem volume growth estimates for different diameter classes of Scots pine (Pinus sylvestris L.) and Norway spruce (Picea abies (L.) Karst.). Our results indicate that both methods are fairly insensitive to random measurement errors of the size that occur in the Swedish NFI. The empirical comparison between the two methods showed greater differences for large diameter trees of both pine and spruce. A likely explanation is that the regressions are uncertain because few large trees were available for developing the models.

\section{Keywords}

National forest inventory, Picea abies, Pinus sylvestris, random measurement errors, stem volume increment, Taylor series expansion 


\section{Introduction}

Long-term monitoring systems are essential for studying the development of forests at national and regional scales and for obtaining data for strategic forest management planning. National forest inventories (NFIs) estimate the current status and change over time of a large number of forest parameters, such as growth and yield of timber resources, carbon stocks, bioenergy potentials, biodiversity, and recreational values (Davis et al. 2001, Backéus et al. 2006, Vainio et al. 2009). Stem volume increment of the major commercial tree species are important estimates for the assessment of sustainable harvesting levels.

Today, the NFIs in most countries are based on sample plot designs (McRoberts et al. 2010, Tomppo et al. 2010). The sample plots are often laid out systematically with a random starting point, and can be temporary, permanent or a combination of both. Permanent sampling units are an important component of many forest monitoring systems due to their capacity to provide appropriate data for estimating change and detecting trends (for example, van Deusen 1989). Growth estimation generally is most efficient when fixed radius plots are used, compared to Bitterlich designs where tree-size dependent inclusion areas may cause substantial variability (Kangas \& Maltamo 2006).

There are two basic approaches to estimate growth at individual tree level (for example, Svensson 1988, Strand \& Li 1990). According to the first method (i) growth is estimated as the difference between volume predictions from two consecutive inventories which requires permanent plots that can be remeasured at certain intervals. Typical input variables in volume functions are tree species, diameter at breast height (dbh), height (h) and crown height (ch) (Näslund 1940, Näslund 1947, Brandel 1990). Method (ii) can be applied on either temporary or permanent plot data from a single survey. Here, growth is estimated directly by a regression model that includes radial increment and tree age as additional independent variables (Svensson 1988). If the inventory consists of both temporary and permanent plots, generally method (i) is applied on permanent plots while method 
(ii) is applied on temporary plots, and the estimates are combined to predict growth for the surveyed area.

A conceptual model (Beers 1962) describes growth between two consecutive inventories as a function of ingrowth, survivor growth, mortality, and cut. Ingrowth represents the volume of trees that were smaller than a certain threshold size at the first inventory but large enough to be included in the second inventory. Survivor growth is the difference in volume for trees included at both occasions, while mortality and cut are removals from the growing stock. Depending on the length of the remeasurement intervals it may be necessary to account for the growth of trees that died or were cut in the time between the inventories in order to increase the precision when estimating growth on permanent plots (for example, Poso 2006). These trees also contributed to the total growth. However, it is often difficult to establish the exact year of death and to quantify the growth accumulated until then.

It is important to understand what factors influence the accuracy of the final estimates. The performance of the described methods for growth estimation at tree level is affected by the sampling design, the correctness of the functions including model selection, the parameter estimation and the material used, non-explained residual variability, and measurement or classification errors in the input variables in applications (cf. Gertner \& Dzialowy 1984, Smith \& Burkhart 1984, Gertner 1986, Kangas 1996, Kangas 1998, Eid 2000, Canavan \& Hann 2004, Pedersen \& Skovsgaard 2009, Mäkinen et al. 2010a). Measurement errors generally receive less attention and are assumed to be relatively small compared to sampling errors and regression function errors (Gertner 1990). Sampling errors normally only give rise to random errors and can be reduced by increasing the sample size. It is known from control inventories that random measurement errors, for variables such as diameter and height, can be substantial even if the systematic errors generally are small (Daamen 1980). Random errors can also lead to increased random variation and systematic errors (bias) in predicted variables due to model non-linearity (for example, Gertner 1991, Pedersen 
\& Skovsgaard 2009). The magnitude of this type of errors can be expected to be different on permanent sample plots compared to temporary sample plots. Also, the error propagation through the functions may be different for method (i) and (ii).

The objective of this study was to evaluate the magnitude of bias introduced by random measurement errors for the two methods to estimate growth at individual tree level. We approached this first theoretically, using Taylor series expansion to assess bias, and also empirically by comparing the outputs from the two methods when applied to a common data set from the Swedish NFI. 


\section{Materials and methods}

\section{NFI data}

The Swedish NFI is carried out annually using a combination of permanent and temporary sample plots (Ranneby et al. 1987, Axelsson et al. 2010). To facilitate field work and improve efficiency in data acquisition, all plots are circular and clustered in square tracts with variable size and spacing depending on five different regions. The inventory is designed as 5 year cycles, which means that the permanent plots generally are remeasured after 5 years but for practical reasons sometimes longer intervals can occur. We extracted a data set from the NFI database that allowed us to compare both growth estimation methods based on the same data. During a limited period (1993-1998) increment cores had been collected also on permanent plots. A subset of plots was then selected with the requirement that they were located on forest land and contained at least one sample tree of the species Scots pine (Pinus sylvestris L.) or Norway spruce (Picea abies (L.) Karst.). Figure 1 shows the geographical location of the selected plots, distributed over the forested area of Sweden.

$>$ Figure 1

All plots used in this study were established in 1983-87. They were remeasured for the first time in 1988-92, and again in 1993-98. Incomplete records were removed from the original data set of 1968 trees, for example observations with missing or incorrectly calculated volumes in the database, or where no radial increment had been registered for the outermost tree ring but survey dates later than July suggested that cell growth had occurred. Some observations were removed because they were measured in the fall of 1993 although the plots belonged to the 1994 sample. The remaining data set comprised 747 plots with 1 to 10 sample trees per plot, in total 1877 trees. The average number of sample trees on a plot was 2.5. An overview of the data is given in Tables I and II.

>Table 1

>Table 2 
Growth estimation in the Swedish NFI

The two methods to estimate volume increment ( $v i$ ) for individual trees are given in general form:

$$
v i_{N}=f_{N}\left(x_{12}, x_{22}, x_{32} \ldots\right)-f_{N}\left(x_{11}, x_{21}, x_{31} \ldots\right)
$$

$$
v i_{S}=f_{S}\left(x_{12}, x_{22}, x_{32} \cdots\right)
$$

where $x_{11}$ denotes input variable 1 at time point 1 , etc. The indices $N$ and $S$ refer to volume functions by Näslund $(1940,1947)$ and growth functions by Svensson (1988), respectively. Current practice in the Swedish NFI is to use Näslund's functions to obtain growth estimates from permanent plot data as volume differences and to apply Svensson's functions for trees on temporary plots. The various required input variables for Scots pine and Norway spruce are explained in the Appendix. In the case of Näslund's volume functions we also need to consider three different regions.

\section{Assessment of bias}

The bias due to random measurement errors in the two methods for growth estimation was evaluated through Taylor approximation. We calculated the theoretical bias based on known measurement error variances for the predictor variables.

First, we linearised the growth functions with general second order Taylor series expansion for the case of several independent variables, i.e.

$$
\begin{aligned}
f\left(x_{1}, x_{2}, x_{3}, \ldots\right) \approx & f\left(x_{10}, x_{20}, x_{30}, \ldots\right) \\
& +\frac{d f}{d x_{10}}\left(x_{1}-x_{10}\right)+\frac{d f}{d x_{20}}\left(x_{2}-x_{20}\right)+\ldots \\
& +\frac{d^{2} f}{2 d x_{10}^{2}}\left(x_{1}-x_{10}\right)^{2}+\frac{d^{2} f}{2 d x_{20}^{2}}\left(x_{2}-x_{20}\right)^{2}+\ldots \\
& +\frac{d^{2} f}{2 d x_{10} d x_{20}}\left(x_{1}-x_{10}\right)\left(x_{2}-x_{20}\right)+\frac{d^{2} f}{2 d x_{10} d x_{30}}\left(x_{1}-x_{10}\right)\left(x_{3}-x_{30}\right)+\ldots
\end{aligned}
$$


Here, $x_{1}, x_{2}, x_{3}, \ldots$ are independent variables and $x_{10}, x_{20}, x_{30}, \ldots$ are the values of these variables at the point around which the function $f$ is approximated. In our applications this point was selected to correspond to the (unknown) true values of the independent variables (which also corresponds to the expected values of the variables $x_{1}, x_{2}, x_{3}, \ldots$ since they deviate from the true values only by random measurement errors).

To obtain a bias formula we rearranged the terms in the previous equation. Asserting that the expected value of the function is fairly well approximated by the function value using the expected values of the independent variables as input, we can express bias as follows

$$
\begin{aligned}
& \text { Bias } \approx E\left[f\left(x_{1}, x_{2}, x_{3}, \ldots\right)\right]-f\left(x_{10}, x_{20}, x_{30}, \ldots\right)= \\
& \sum_{i=1}^{p} \frac{d^{2} f}{2 d x_{i 0}{ }^{2}} \operatorname{Var}\left(x_{i}\right)+\sum_{i=1}^{p} \sum_{j=1}^{q} \frac{d^{2} f}{2 d x_{i 0} d x_{j 0}} \operatorname{Cov}\left(x_{i}, x_{j}\right)
\end{aligned}
$$

All first order terms disappear according to the assumption $E\left(x_{i}-x_{i 0}\right)=0$. The bias can be estimated by a sum of second order derivatives evaluated at the true values of the variables (in our calculations the actual values from the NFI were used as approximations) multiplied with measurement error variances for the different variables. If the measurement errors are correlated the corresponding covariance term will be non-zero, and the covariance terms will also affect the bias. In case of non-correlated errors the covariances are zero.

The general principle described above was applied to the functions by Näslund $(1940,1947)$ and Svensson (1988) and the specific formulas are provided in the Appendix.

Comparison of growth estimation methods (i) and (ii)

The bias formulas were applied to the data from the Swedish NFI, using measurement error variances (and covariances) from studies by Broman and Christoffersson (1999) and Berg Lejon (2003). These measurement errors were obtained from control surveys within the Swedish NFI, which may be better described as measurement variability studies as the measurement error 
variances are derived based on an assumption of two independent measurements of the same attribute (Westfall \& Patterson 2007). For several tree-level attributes that affect the tree volume estimates, i.e. dbh, tree $h$, ch, and bark thickness (b), the measurement error variances were described by linear functions of $\mathrm{dbh}$ for each species. The random error for the variable crown length (cl) was derived from tree height and crown height where we assumed a correlation of 0.5 between the measurement errors of these variables on the same tree. The error variances for the tree-level attributes in method (ii) such as 5 year radial increment and tree age at breast height were assumed to be independent of tree size. The measurement errors in terms of standard deviation for $\mathrm{dbh}$ and $\mathrm{h}$ are given in figure 2 . The levels are similar to those reported by Päivinen and Yli-Kojola (1989).

$>$ Figure 2

To study the influence of measurement errors on bias, we evaluated the theoretical bias not only for the level of measurement errors in the NFI as estimated by Broman and Christoffersson (1999) and Berg Lejon (2003) but also for error levels (variances) that were twice and four times as large as the baseline.

For the empirical comparison we used the same NFI data set for growth estimates according to methods (i) and (ii). All required variables including measurements of radial increment and tree age were available from this set of permanent plots. While the regression model for method (ii) always provides growth estimates for the last five years, the values obtained by method (i) need to be adjusted. Remeasurement intervals of 5-6 calendar years actually corresponded to a range of 4-7 growing seasons depending on when the plots were visited. To make the methods comparable, we developed a function based on the geographical location of each plot and the date of inventory and applied a correction factor $5 / z$ to the observed growth, where $z$ is the actual number of growing seasons. Start and length of the growing season were determined from the variables latitude and altitude (Morén \& Perttu 1994). These functions by Morén \& Perttu (1994) were derived for a 
temperature threshold value of $+5{ }^{\circ} \mathrm{C}$ and altitudes below $1000 \mathrm{~m}$ a.s.l. and do not take into account any variation between different years. The length of the growing season in the NFI data set for this study ranged from 114 days in the north to 215 days in the south of Sweden. The sigmoid curve of the general shape $\mathrm{y}=\left[1+\exp \left(\mathrm{b}_{0} *\left(\mathrm{~b}_{1}-(\mathrm{x})\right)\right)\right]^{-1}$ describes the proportion of volume growth as a function of time, i.e. the part of the growing season that has passed before the inventory. The parameters $b_{0}$ and $b_{1}$ were estimated by using the average radial increment of the previous 5 years (avg5) as a reference for the ring width (rw) measured during the current year as an approximation, rw/avg5 $=[1+\exp (10.6 *(0.42-(\mathrm{d} / \text { gs5 })))]^{-1}+\varepsilon \mathrm{p}+\varepsilon \mathrm{t}$ where $d$ stands for the number of days counted from the beginning of the growing season to the date of inventory, gs5 is the length of the growing season, and $\varepsilon p$ and $\varepsilon t$ are random errors at plot and tree level, respectively. For this, we applied the NLMIXED procedure in SAS ${ }^{\circledR}$ software (SAS Institute Inc. 2004).

After adjusting the volume growth values according to method (i) with regard to growing seasons the empirical difference was calculated as:

$\Delta v i=v i_{N}-v i_{S}$ where $v i_{N}$ refers to method (i) and $v i_{S}$ to method (ii).

We performed pairwise comparisons at individual tree level to evaluate whether there was a significant difference between the two methods for pine and spruce trees in different diameter classes. Plot averages were used when several trees occurred on the same plot. To evaluate if we had eliminated the effect of varying growth periods for method (i) a simple regression analysis was applied with the empirical difference as the dependent variable and the number of growing seasons as the independent variable. No significant trends over interval length remained in the data. 


\section{Results}

The magnitude of bias introduced by random measurement errors was generally very small for both growth estimation methods. There was a slight trend with increasing $\mathrm{dbh}$ for Norway spruce, positive for method (i) and negative for method (ii), which increased the difference between the methods for large trees. The maximum theoretical differences to be expected from our bias estimates were 0.05 and $0.16 \mathrm{dm}^{3}$ for Scots pine and Norway spruce, respectively, for trees in the largest dbh classes. The variation was much greater when studying the empirical difference between actual growth estimates obtained by method (i) and (ii). However, the difference was only significant for pines larger than 45 $\mathrm{cm}$ and spruces smaller than $15 \mathrm{~cm}$ at the $5 \%$ error level. Overall, method (i) produced larger estimates than method (ii) for Scots pine, but the opposite was the case for Norway spruce. A summary of the results is presented in Table III, where the tree level biases were averaged within size classes.

$>$ Table 3

The increased bias for the simulated levels of random measurement errors in the explanatory variables for volume increment is shown in Figure 3. The estimated bias is always less than 1.5 percent of the estimated volume increment for both methods and investigated levels of measurement errors.

$>$ Figure 3 


\section{Discussion}

Today's large-scale NFIs often have a sampling design where field data from both permanent and temporary sample plots are collected and there is a need to combine growth estimates derived from different methods. Therefore it is important that the applied models provide similar results, especially considering that the precision of measurements may vary between permanent and temporary plots (e.g. Broman \& Christoffersson 1999). Since they were introduced in 1983, the share of permanent sample plots has increased considerably in the Swedish NFI. Currently they make up more than half of the newly established plots (Nilsson et al. 2011). This implies that estimates of volume increment according to volume differences now influence the final growth estimates that are reported at county and national level more than in earlier decades.

The data set we chose for this study was limited by the initial requirement that increment cores had been collected in addition to the usual assessment of permanent sample plots. Since this was only done during a short period, the material was not sufficient to quantify the difference between the models. But we could see in the empirical study that the two methods lead to similar results regarding estimated volume increment for both pine and spruce and for all diameter classes except the very large trees. There may be many different reasons for this. Most plausible is that the models by Svensson are uncertain for large diameters because they were only underpinned by few large trees. Svensson (1988) fixed the effect of the variable $\ln (\mathrm{dbh})$ by altering the response variable $\ln (\mathrm{vi})$ to $\ln (\mathrm{vi})-\ln (\mathrm{dbh}))$ to avoid overestimations for large trees. A conclusion of the present study is that further analyses concerning the volume increment predictions on large trees for method (ii) could be motivated. Overall no substantial trends were revealed when studying growth estimation residual errors over the independent variables included in the functions.

The main finding of this study was that both growth estimation methods appear to be rather insensitive to random measurement errors when these have a magnitude corresponding to that of the Swedish NFI. However, when increasing the size of random errors the bias also increased, 
although not above $1.5 \%$. Measurement error levels of higher magnitude may occur in other practical large-scale inventories that are not as rigorously controlled as NFIs generally are. Also, compared to sampling error, the error due to measurement variation tends to be rather small (Westfall \& Patterson 2007). Both approaches can apparently be safely applied to estimate growth from inventory data. However, it should be noted that whenever a method based on data from one time point only is applied, it will be difficult to estimate the contribution to the total growth by harvested trees or trees that have died for other reasons during the period. By repeated measurements, it is easier to obtain a complete picture of the stand development on the plot, although even in this case it may be difficult to estimate the growth on trees that have died or been cut.

The theoretical bias we estimated for individual trees was very small and can probably be neglected in larger contexts where country-level forest growth scenarios, total biomass or carbon budgets are modeled. It is difficult to evaluate the magnitude of bias when, for example, models are extrapolated. Unpublished research (concerning large scale estimates at national level based on NFI data) indicates that the sampling variance dominates the error structure. More important than random measurement errors are the effects of misclassification or model errors. To correct for measurement errors requires knowledge of the error distribution (Canavan \& Hann 2004). Outlier detection methods are available to check for assessment errors in inventory data and thus can be used to enhance data reliability (Mäkinen et al. 2010b). Gertner \& Köhl (1992) found that the survey system for the First Swiss NFI was rather insensitive to random errors but not to systematic measurement errors. 


\section{Acknowledgments}

We thank Bertil Westerlund from the Swedish National Forest Inventory for excellent help in providing NFI data and valuable discussions along the way. The study was supported by FORMAS. 


\section{Appendix}

Here, we describe how the formulas for bias were developed.

Method (i), volume increment vi on permanent plots, is based on Näslund's $(1940,1947)$ volume functions for individual trees and calculated as the difference between the volumes inside bark measured at the two surveys with usually a 5 year interval between volume estimates $v_{1}$ and $v_{2}$. $v i=v_{2}-v_{1}$

The volume of Scots pine for northern Sweden is:

$v=\alpha_{1}(d b h)^{2}+\alpha_{2}(d b h)^{2} \cdot h+\alpha_{3}(d b h)^{2} \cdot c+\alpha_{4}(d b h) \cdot h \cdot b$

for southern and central Sweden:

$v=\alpha_{1}(d b h)^{2}+\alpha_{2}(d b h)^{2} \cdot h+\alpha_{3}(d b h)^{2} \cdot c+\alpha_{4}(d b h) \cdot h^{2}+\alpha_{5}(d b h) \cdot h \cdot b$

and for Norway spruce in all three regions:

$v=\alpha_{1}(d b h)^{2}+\alpha_{2}(d b h)^{2} \cdot h+\alpha_{3}(d b h)^{2} \cdot c+\alpha_{4}(d b h) \cdot h^{2}+\alpha_{5} h^{2}$

where dbh stands for diameter at breast height inside bark $(\mathrm{cm}), \mathrm{h}$ is the tree height and $\mathrm{c}$ the live crown base in meters, and $b$ denotes double bark thickness $(\mathrm{mm})$. The unit for volume $v$ is $\mathrm{dm}^{3}$. All parameters $\alpha$ can be found in Näslund $(1940,1947)$.

For method (ii), or volume increment on temporary plots, Svensson's (1988) growth functions (without form quotients as predictor variables) are used. Scots pine growth is expressed as $v i=e^{\alpha_{0}+\alpha_{1}(d b h)+\alpha_{2} \ln (d b h)+\alpha_{3} \ln h+\alpha_{4} \ln d i+\alpha_{5} \ln c r+\alpha_{6} a+\alpha_{7} \ln a}$ and Norway spruce growth as $v i=e^{\alpha_{0}+\alpha_{1} \ln (d b h)+\alpha_{2} h+\alpha_{3} \ln h+\alpha_{4} d i+\alpha_{5} \ln d i+\alpha_{6} c r+\alpha_{7} \ln c r+\alpha_{8} a+\alpha_{9} \ln a}$ where vi is the volume increment inside bark for 5 years, not including the year of inventory $(1 / 100$ $\left.\mathrm{dm}^{3}\right)$, dbh is diameter at breast height inside bark $(\mathrm{mm}), \mathrm{h}$ is tree height in $\mathrm{dm}$, di stands for diameter increment for the outermost 5 tree rings, not including the year of inventory $(1 / 10 \mathrm{~mm}), \mathrm{cr}$ is the 
crown ratio in unit $1 / 1000$ (crown length divided by tree height), and a is the age at breast height. Parameters are available in Svensson (1988).

Calculation of expected bias in methods (i) and (ii) was done as follows.

Bias was defined as "Expected value - True value" and approximated by Taylor series with second derivatives multiplied with measurement error variances:

$E\left[f\left(x_{1}, x_{2}, x_{3}, \ldots\right)\right]-f\left(x_{10}, x_{20}, x_{30}, \ldots\right)=\frac{d^{2} f}{2 d x_{10}{ }^{2}} \operatorname{Var}\left(x_{1}\right)+\frac{d^{2} f}{2 d x_{20}{ }^{2}} \operatorname{Var}\left(x_{2}\right)+\ldots$

First order derivatives and all covariance terms equal zero and could be deleted. Measurement error levels came from Broman \& Christoffersson (1999) where the standard deviations and variances for the variables of interest, such as height, crown height and bark thickness, are functions of $\mathrm{dbh}$ outside bark. We used the error levels presented for permanent plots in the report and calculated the variances for our data consisting of 1877 individual trees. For measurement errors in variables obtained from increment cores like ring width and tree age at breast height, we had access to a study that compared WinDendro with traditional microscope measuring routines in the NFI (Berg Lejon 2003). This gave us the magnitude of error in these variables. The variances 1.86 for tree age and 10.42 for 5 -year diameter increment $(1 / 10 \mathrm{~mm})$ were applied for all trees.

The resulting bias formulas are:

Method (i), Scots pine, north

Bias $=\left(2 \alpha_{1}+2 \alpha_{2} h_{2}+2 \alpha_{3} c_{2}\right) * \operatorname{Var}(d b h)_{2}+\left(-2 \alpha_{1}-2 \alpha_{2} h_{1}-2 \alpha_{3} c_{1}\right) * \operatorname{Var}(d b h)_{1}$

Method (i), Scots pine, south or central region

$$
\begin{aligned}
\text { Bias } & =\left(2 \alpha_{1}+2 \alpha_{2} h_{2}+2 \alpha_{3} c_{2}\right) * \operatorname{Var}(d b h)_{2}+\left(-2 \alpha_{1}-2 \alpha_{2} h_{1}-2 \alpha_{3} c_{1}\right) * \operatorname{Var}(d b h)_{1} \\
& +\left(2 \alpha_{4}(d b h)_{2}\right) * \operatorname{Var}\left(h_{2}\right)+\left(-2 \alpha_{4}(d b h)_{1}\right) * \operatorname{Var}\left(h_{1}\right)
\end{aligned}
$$


Method (i), Norway spruce, all regions

$$
\begin{aligned}
\text { Bias } & =\left(2 \alpha_{1}+2 \alpha_{2} h_{2}+2 \alpha_{3} c_{2}\right) * \operatorname{Var}(d b h)_{2}+\left(-2 \alpha_{1}-2 \alpha_{2} h_{1}-2 \alpha_{3} c_{1}\right) * \operatorname{Var}(d b h)_{1} \\
& +\left(2 \alpha_{4}(d b h)_{2}+2 \alpha_{5}\right) * \operatorname{Var}\left(h_{2}\right)+\left(-2 \alpha_{4}(d b h)_{1}-2 \alpha_{5}\right) * \operatorname{Var}\left(h_{1}\right)
\end{aligned}
$$

Method (ii), Scots pine

$$
\begin{aligned}
\text { Bias } & =\left(\left(\alpha_{1}+\frac{\alpha_{2}}{(d b h)}\right)^{2} e^{\alpha_{0}+\alpha_{1}(d b h)+\alpha_{2} \ln (d b h)+\alpha_{3} \ln h+\alpha_{4} \ln d i+\alpha_{5} \ln c r+\alpha_{6} a+\alpha_{7} \ln a}-\frac{\alpha_{2}}{(d b h)^{2}} e^{(\ldots)}\right) * \operatorname{Var}(d b h) \\
& +\left(\left(\frac{\alpha_{3}}{h}\right)^{2} e^{(\ldots)}-\frac{\alpha_{3}}{h^{2}} e^{(\ldots)}\right) * \operatorname{Var}(h)+\left(\left(\frac{\alpha_{4}}{d i}\right)^{2} e^{(\ldots)}-\frac{\alpha_{4}}{d i^{2}} e^{(\ldots)}\right) * \operatorname{Var}(d i) \\
& +\left(\left(\frac{\alpha_{5}}{c r}\right)^{2} e^{(\ldots)}-\frac{\alpha_{5}}{c r^{2}} e^{(\ldots)}\right) * \operatorname{Var}(c r)+\left(\left(\alpha_{6}+\frac{\alpha_{7}}{a}\right)^{2} e^{(\ldots)}-\frac{\alpha_{7}}{a^{2}} e^{(\ldots)}\right) * \operatorname{Var}(a)
\end{aligned}
$$

Method (ii), Norway spruce

$$
\begin{aligned}
\text { Bias } & =\left(\left(\frac{\alpha_{1}}{(d b h)}\right)^{2} e^{\alpha_{0}+\alpha_{1} \ln (d b h)+\alpha_{2} h+\alpha_{3} \ln h+\alpha_{4} d i+\alpha_{5} \ln d i+\alpha_{6} c r+\alpha_{7} \ln c r+\alpha_{8} a+\alpha_{9} \ln a}-\frac{\alpha_{1}}{(d b h)^{2}} e^{(\ldots)}\right) \\
& * \operatorname{Var}(d b h)+\left(\left(\alpha_{2}+\frac{\alpha_{3}}{h}\right)^{2} e^{(\ldots)}-\frac{\alpha_{3}}{h^{2}} e^{(\ldots)}\right) * \operatorname{Var}(h)+\left(\left(\alpha_{4}+\frac{\alpha_{5}}{d i}\right)^{2} e^{(\ldots)}-\frac{\alpha_{5}}{d i^{2}} e^{(\ldots)}\right) * \operatorname{Var}(d i) \\
& +\left(\left(\alpha_{6}+\frac{\alpha_{7}}{c r}\right)^{2} e^{(\ldots)}-\frac{\alpha_{7}}{c r^{2}} e^{(\ldots)}\right) * \operatorname{Var}(c r)+\left(\left(\alpha_{8}+\frac{\alpha_{9}}{a}\right)^{2} e^{(\ldots)}-\frac{\alpha_{9}}{a^{2}} e^{(\ldots)}\right) * \operatorname{Var}(a)
\end{aligned}
$$

All parameters $\alpha$ are the same as in the original formulas by Näslund (1947) and Svensson (1988), respectively. 


\section{Tables}

Table I. Number of plots and sample trees per year. The remeasurement intervals were 5 years for southern Sweden in 1993 and 6 years for all other periods.

\begin{tabular}{|c|c|c|c|c|c|}
\hline \multirow[b]{2}{*}{ Survey year } & \multirow[b]{2}{*}{ Previous survey } & \multirow[b]{2}{*}{ Plots established } & \multirow[b]{2}{*}{ No. of plots } & \multicolumn{2}{|c|}{ No. of sample trees } \\
\hline & & & & Scots pine & Norway spruce \\
\hline 1993 & 1988 (south) & 1983 & 110 & 114 & 140 \\
\hline 1994 & 1988 (north) & 1983 & 114 & 154 & 118 \\
\hline 1995 & 1989 & 1984 & 140 & 225 & 151 \\
\hline 1996 & 1990 & 1985 & 122 & 171 & 145 \\
\hline 1997 & 1991 & 1986 & 126 & 158 & 177 \\
\hline 1998 & 1992 & 1987 & 135 & 162 & 162 \\
\hline total & & & 747 & 984 & 893 \\
\hline
\end{tabular}


Table II. Summary of tree data per diameter (dbh) class of Scot pine and Norway spruce. The reported values are the means of the measurements from the last survey (1993-98). Volume increment (vi) according to method (i) has been corrected to correspond to 5 year intervals for comparison with growth model (ii).

\begin{tabular}{|c|c|c|c|c|c|c|c|c|}
\hline Species & Diameter & $\mathrm{N}$ & Height & Age & $5-y r$ inc ${ }^{a}$ & Volume & vi (i) & vi (ii) \\
\hline & {$[\mathrm{cm}(\mathrm{dbh})]$} & & $(\mathrm{dm})$ & (years) & $(\mathrm{mm})$ & $\left(\mathrm{dm}^{3}\right)$ & $\left(\mathrm{dm}^{3}\right)$ & $\left(\mathrm{dm}^{3}\right)$ \\
\hline \multirow[t]{6}{*}{ Scots pine } & $5-14.9$ & 134 & 104 & 48 & 10.8 & 55 & 13.15 & 13.38 \\
\hline & $15-24.9$ & 372 & 149 & 66 & 12.4 & 197 & 33.15 & 33.50 \\
\hline & $25-34.9$ & 323 & 195 & 99 & 10.1 & 537 & 53.60 & 52.62 \\
\hline & $35-44.9$ & 132 & 216 & 109 & 11.3 & 968 & 83.60 & 75.68 \\
\hline & $45-$ & 23 & 233 & 129 & 11.7 & 1646 & 171.50 & 95.06 \\
\hline & Mean & & 169 & 82 & 11.3 & 427 & 47.14 & 44.14 \\
\hline \multirow[t]{6}{*}{ Norway spruce } & $5-14.9$ & 199 & 102 & 55 & 10.4 & 53 & 11.76 & 12.63 \\
\hline & $15-24.9$ & 366 & 165 & 67 & 13.3 & 223 & 38.98 & 39.62 \\
\hline & $25-34.9$ & 214 & 216 & 81 & 13.1 & 599 & 73.60 & 76.78 \\
\hline & $35-44.9$ & 96 & 256 & 86 & 16.1 & 1173 & 136.78 & 132.55 \\
\hline & $45-$ & 18 & 289 & 84 & 16.7 & 2009 & 133.97 & 192.77 \\
\hline & Mean & & 175 & 70 & 13.0 & 413 & 53.64 & 55.59 \\
\hline
\end{tabular}


Table III. Expected differences due to theoretical bias and empirical differences in growth estimates between methods (i) and (ii) for Scots pine and Norway spruce.

\begin{tabular}{|c|c|c|c|c|c|c|c|}
\hline Species & {$[\mathrm{cm}(\mathrm{dbh})]$} & $\mathrm{N}$ & $\left(\mathrm{dm}^{3}\right)$ & $\left(\mathrm{dm}^{3}\right)$ & $\begin{array}{l}\text { Expected difference } \\
\qquad \begin{array}{c}\text { [bias (i) - bias (ii) } \\
\left.\left(\mathrm{dm}^{3}\right)\right]\end{array}\end{array}$ & $\begin{array}{l}\text { Empirical difference } \\
\text { [growth (i) - growth (ii) } \\
\left.\qquad\left(\mathrm{dm}^{3}\right)\right]\end{array}$ & P-value ${ }^{a}$ \\
\hline \multicolumn{8}{|l|}{ Scots } \\
\hline pine & $5-14.9$ & 104 & 0.01 & 0.01 & -0.00 & -0.33 & 0.25 \\
\hline & $15-24.9$ & 239 & 0.01 & 0.01 & 0.01 & -0.14 & 0.82 \\
\hline & $25-34.9$ & 211 & 0.01 & -0.01 & 0.03 & 1.29 & 0.43 \\
\hline & $35-44.9$ & 105 & 0.02 & -0.01 & 0.03 & 7.98 & 0.07 \\
\hline & $45-$ & 21 & 0.04 & -0.01 & 0.05 & 72.90 & $<.01$ \\
\hline & all & 680 & 0.01 & -0.00 & 0.02 & 3.78 & $<.01$ \\
\hline \multicolumn{8}{|l|}{ Norway } \\
\hline spruce & $5-14.9$ & 161 & 0.01 & -0.00 & 0.01 & -0.92 & $<.01$ \\
\hline & $15-24.9$ & 253 & 0.02 & -0.01 & 0.03 & -1.35 & 0.06 \\
\hline & $25-34.9$ & 149 & 0.03 & -0.03 & 0.07 & -2.61 & 0.36 \\
\hline & $35-44.9$ & 68 & 0.06 & -0.05 & 0.11 & 5.09 & 0.43 \\
\hline & $45-$ & 17 & 0.07 & -0.09 & 0.16 & -61.18 & 0.11 \\
\hline & all & 648 & 0.03 & -0.02 & 0.05 & -2.43 & 0.08 \\
\hline
\end{tabular}


Figures

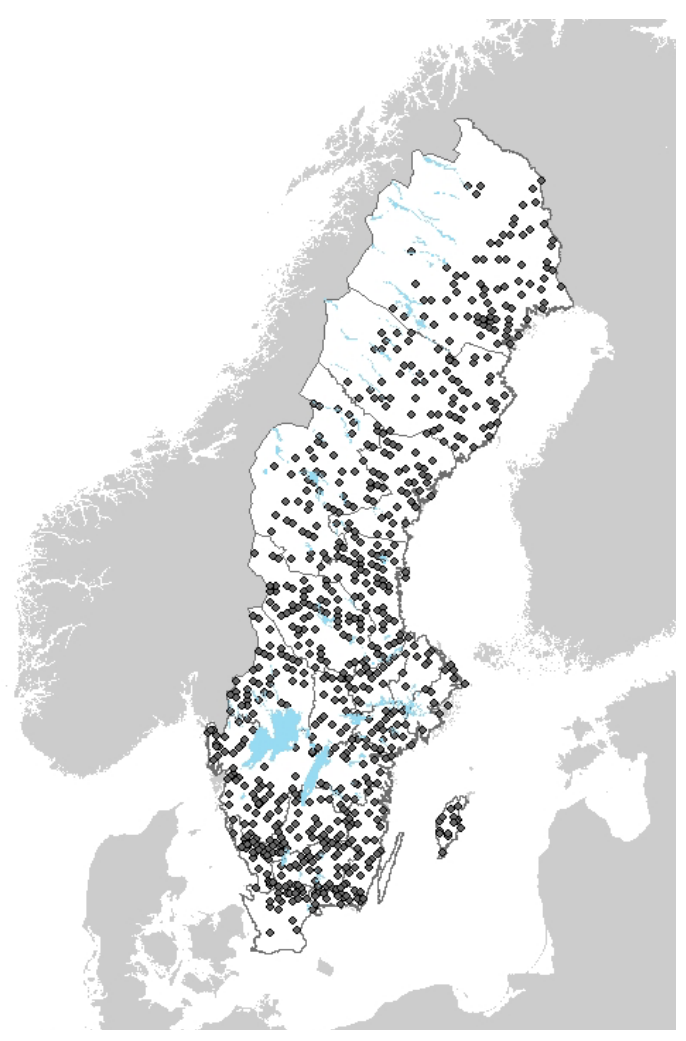

Figure 1. Location of the selected permanent NFI plots from 1993-98.
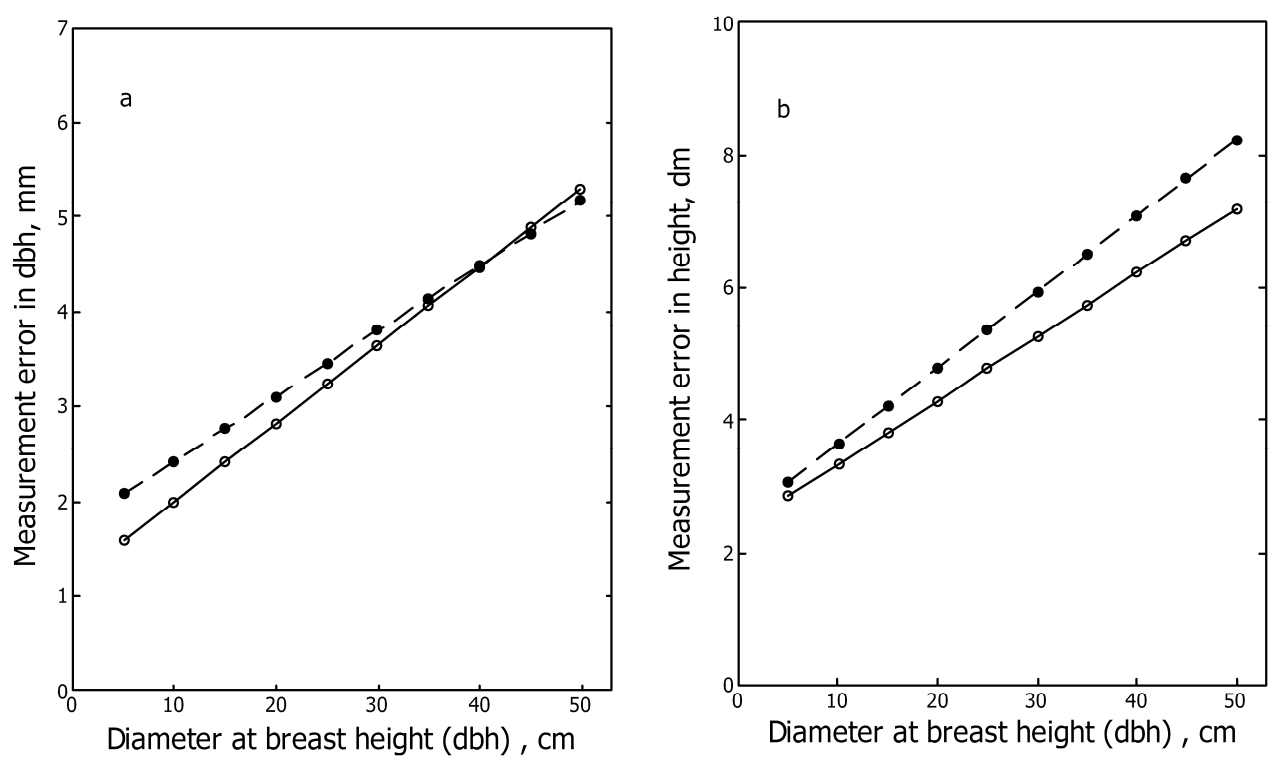
Figure 2. Standard deviation of measurement errors associated with diameter at breast height (a) and tree height (b) as a function of dbh for Scots pine $(\bullet)$ and Norway spruce (o).
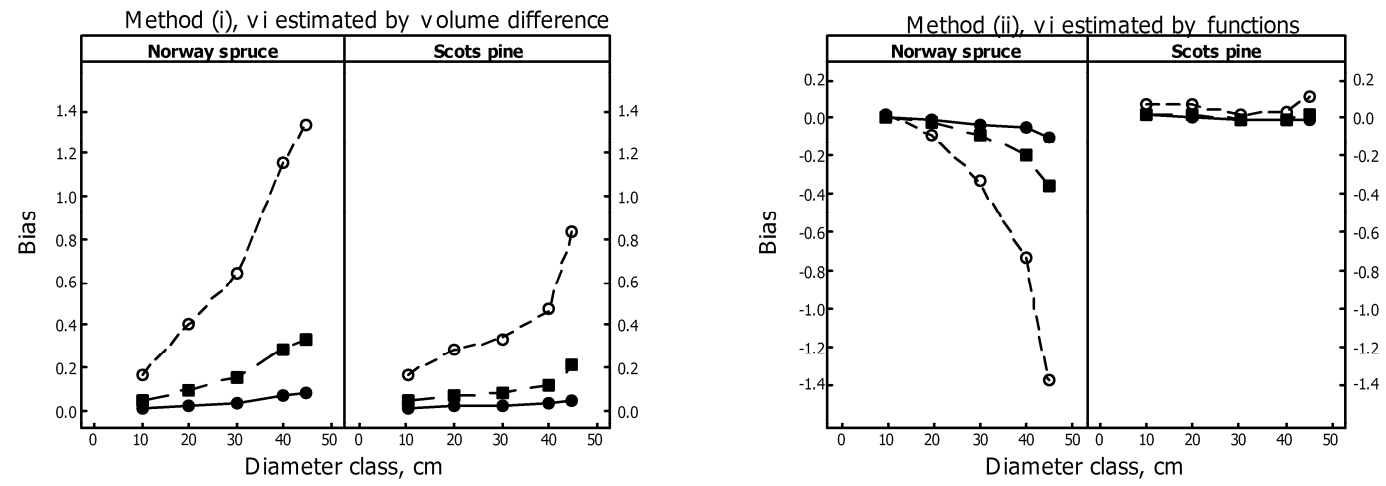

Method (i), vi estimated by volume difference
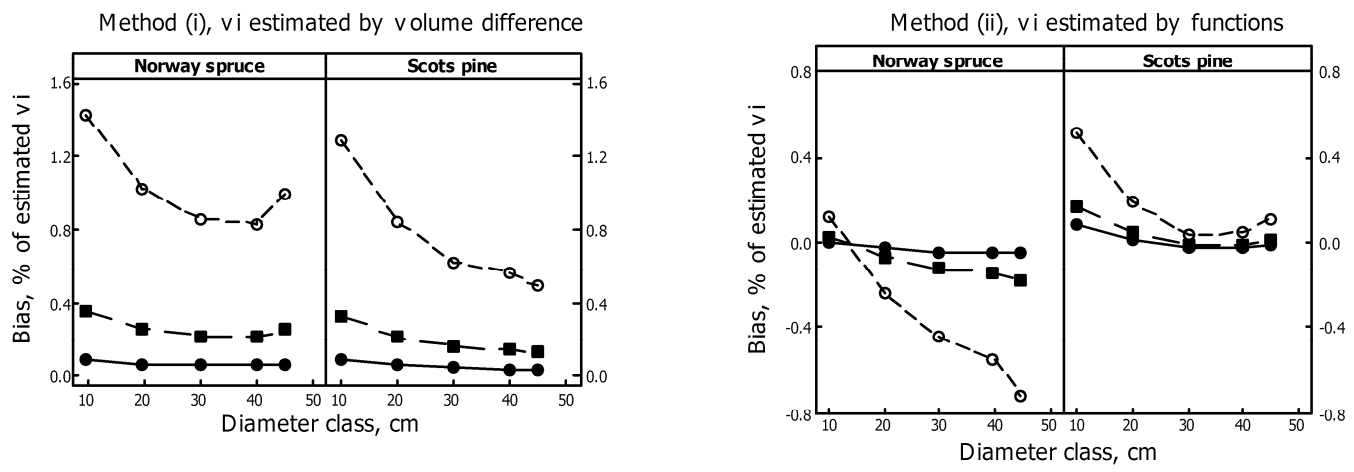

Figure 3. Theoretical bias for method (i) and (ii) shown as absolute values $\left(\mathrm{dm}^{3}\right)$ and as a percentage of the estimated volume increment. Measurement error levels are normal $(\bullet)$, twice $(\boldsymbol{\square})$ and four times (o) as large as normal. 


\section{References}

Axelsson, A. L., Ståhl, G., Söderberg, U., Petersson, H., Fridman, J. \& Lundström, A. (2010). Development of Sweden's National Forest Inventory. In: Tomppo, E., Gschwantner, T., Lawrence, M. \& McRoberts, R. E. (Eds.) National forest inventories: pathways for common reporting. p. 612. Dordrecht: Springer.

Backéus, S., Wikström, P. \& Lämås, T. (2006). Modeling carbon sequestration and timber production in a regional case study. Silva Fennica 40(4), 615-629.

Beers, T. W. (1962). Components of forest growth. Journal of Forestry 60(4), 245-248.

Berg Lejon, S. (2003). Studie av mätmetoder vid Riksskogstaxeringens årsringsmätning. [Study of methods for measuring tree rings at the Swedish National Forest Inventory]. (Arbetsrapport No. 110). Umeå, Swedish University of Agricultural Sciences. (In Swedish).

Brandel, G. (1990). Volume functions for individual trees. Doctoral dissertation, Swedish University of Agricultural Sciences, Garpenberg.

Broman, N. \& Christoffersson, J. (1999). Mätfel i provträdsvariabler och dess inverkan på precision och noggrannhet i volymskattningar. [Measurement errors in sample tree variables and their impact on precision and accuracy in volume estimation]. (Arbetsrapport No. 61). Umeå, Swedish University of Agricultural Sciences. (In Swedish).

Canavan, S. J. \& Hann, D. W. (2004). The two-stage method for measurement error characterization. Forest Science 50(6), 743-756.

Daamen, W. (1980). Kontrolltaxeringen åren 1973-1977: resultat från en kontroll av datainsamlingen vid riksskogstaxeringen. [Results from a check on data collection of the national forest survey in 1973-1977]. (Rapport No. 27). Umeå, Swedish University of Agricultural Sciences. (In Swedish).

Davis, L. S., Johnson, K. N., Bettinger, P. S. \& Howard, T. E. (2001). Forest Management: to sustain ecological, economic and social values.(4th ed.). New York: McGraw-Hill.

Eid, T. (2000). Use of uncertain inventory data in forestry scenario models and consequential incorrect harvest decisions. Silva Fennica 34(2), 89-100.

Gertner, G. (1986). Postcalibration sensitivity procedure for regressor variable errors. Canadian Journal of Forest Research 16(5), 1120-1123.

Gertner, G. (1991). Prediction bias and response surface curvature. Forest Science 37(3), 755-765.

Gertner, G. \& Köhl, M. (1992). An assessment of some nonsampling errors in a national survey using an error budget. Forest Science 38(3), 525-538.

Gertner, G. Z. \& Dzialowy, P. J. (1984). Effects of measurement errors on an individual tree-based growth projection system. Canadian Journal of Forest Research 14(3), 311-316.

Gertner, G. Z. (1990). The sensitivity of measurement error in stand volume estimation. Canadian Journal of Forest Research 20(6), 800-804.

Kangas, A. (1996). On the bias and variance in tree volume predictions due to model and measurement errors. Scandinavian Journal of Forest Research 11(3), 281-290.

Kangas, A. \& Maltamo, M. (Eds.) (2006). Forest inventory: methodology and applications. Dordrecht: Springer. (Managing Forest Ecosystems; 10).

Kangas, A. S. (1998). Effect of errors-in-variables on coefficients of a growth model and on prediction of growth. Forest Ecology and Management 102(2-3), 203-212.

McRoberts, R. E., Tomppo, E. O. \& Naesset, E. (2010). Advances and emerging issues in national forest inventories. Scandinavian Journal of Forest Research 25(4), 368-381.

Morén, A.-S. \& Perttu, K. L. (1994). Regional temperature and radiation indices and their adjustment to horizontal and inclined forest land. (Studia Forestalia Suecica No. 194). Uppsala, Swedish University of Agricultural Sciences.

Mäkinen, A., Kangas, A. \& Mehtätalo, L. (2010a). Correlations, distributions, and trends in forest inventory errors and their effects on forest planning. Canadian Journal of Forest Research 40(7), 1386-1396. 
Mäkinen, A. M., Kangas, A. S. \& Tokola, T. (2010b). Identifying the presence of assessment errors in forest inventory data by data mining. Forest Science 56(3), 301-312.

Nilsson, P., Cory, N. \& Dahlgren, J. (2011). Skogsdata: aktuella uppgifter om de svenska skogarna från Riksskogstaxeringen [Forestry Statistics]. Umeå, Swedish University of Agricultural Sciences. (In Swedish).

Näslund, M. (1940). Funktioner och tabeller för kubering av stående träd: tall, gran och björk i norra Sverige. [Functions and tables for computing the cubic volume of standing trees : pine, spruce and birch in northern Sweden]. Meddelanden från Statens skogsförsöksanstalt 32(4), 87-142.

Näslund, M. (1947). Funktioner och tabeller för kubering av stående träd: tall, gran och björk i södra Sverige samt $i$ hela landet. [Functions and tables for computing the cubic volume of standing trees: pine, spruce and birch in southern Sweden, and in the whole of Sweden]. Meddelanden från Statens skogsforskningsinstitut 36(3), 81 pp.

Pedersen, R. Ф. \& Skovsgaard, J. P. (2009). Impact of bias in predicted height on tree volume estimation: A case-study of intrinsic nonlinearity. Ecological Modelling 220(20), 2656-2664.

Poso, S. (2006). Change monitoring with permanent sample plots. In: Kangas, A. \& Maltamo, M. (Eds.) Forest inventory: methodology and applications. pp. 65-84. Dordrecht: Springer.

Päivinen, R. \& Yli-Kojola, H. (1989). Permanent sample plots in large-area forest inventory. Silva Fennica 23(3), 243-252.

Ranneby, B., Cruse, T., Hägglund, B., Jonasson, H. \& Swärd, J. (1987). Designing a new national forest survey for Sweden. (Studia Forestalia Suecica No. 177). Uppsala, Swedish University of Agricultural Sciences.

SAS Institute Inc. (2004). SAS/STAT ${ }^{\circledR} 9.1$ User's guide. Cary, NC, USA: SAS Institute Inc.

Smith, J. L. \& Burkhart, H. E. (1984). A simulation study assessing the effect of sampling for predictor variable values on estimates of yield. Canadian Journal of Forest Research 14(3), 326-330.

Strand, L. \& Li, L. (1990). Determination of volume increment on single trees of Norway spruce. Scandinavian Journal of Forest Research 5(4), 513-524.

Svensson, S. A. (1988). Estimation of annual stem volume increment: a method to be applied to sample trees of Scots pine and Norway spruce on temporary plots in the Swedish national forest inventory. Doctoral dissertation, Swedish University of Agricultural Sciences, Umeå.

Tomppo, E., Gschwantner, T., Lawrence, M. \& McRoberts, R. E. (Eds.) (2010). National forest inventories: pathways for common reporting. Dordrecht: Springer.

Vainio, P., Tokola, T., Palander, T. \& Kangas, A. (2009). A GIS-based stand management system for estimating local energy wood supplies. Biomass \& Bioenergy 33(9), 1278-1288.

van Deusen, P. C. (1989). Multiple-occasion partial replacement sampling for growth components. Forest Science 35(2), 388-400.

Westfall, J. A. \& Patterson, P. L. (2007). Measurement variability error for estimates of volume change. Canadian Journal of Forest Research 37(11), 2201-2210. 